\title{
O Estado Social de Direito, a Proibição de Retrocesso e a Garantia Fundamental da Propriedade
}

$$
\text { Ongo Wolfgang Oaxlet }
$$

Juiz de Direito no RS. Doutor em Direito pela Universidade de Munique, Alemanha. Professor de Direito Constitucional na Escola Superior da Magistratura do RS, na Escola Superior de Direito Municipal e na PUC/RS, onde também leciona no Mestrado em Direito.

SUMÁRIO
I. Considerações introdutórias: a crise do
Estado Social de Direito e a problemática
da proteção dos níveis vigentes de seguran-
ça social;
II. A garantia fundamental da proprie-
dade e a proteção constitucional de posições
jurídicas sociais prestacionais;
III. Outras possibilidades de proteção
constitucional das posições jurídicas soci-
ais de direito público: uma visão panorâmi-
ca;
IV. Considerações finais, inclusive em
nivel de direito comparado;
V. Referências bibliográficas.

\section{Considerações}

introdutórias: a crise do

Estado Social de Direito e a problemática da proteção dos níveis vigentes de segurança social

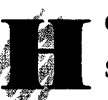

oje, mais do que nunca, constatase que a problemática da sobrevivência do assim denominado Estado Social de Direito constitui um dos temas centrais da nossa época. A já corriqueira afirmativa de que o Welfare State ou Estado-Providência se encontra gravemente enfermo, ${ }^{1}$ além de constantemente submetido à prova, não perdeu, portanto, sua atualidade. Que as discussões de longe já não se restringem mais à esfera da análise política, sócio-econômica e jurídica, mas se transformaram na preocupação de larga parcela

1. Neste sentido, entre outros, $P$. Rosanvallon, $A$ Crise do Estado-Providência, 1997, analisando o problema especialmente com base na experiência francesa. 
da humanidade pela manutenção de seu padrão de vida e até mesmo pela sua sobrevivência, verifica-se não apenas a partir da especial atenção dedicada ao tema nos meios de comunicação, mas pelo fato de que cada ser humano, em maior ou menor grau, acaba sendo atingido pela crise. Cada elevação de tributos, cada redução nos níveis prestacionais do Estado e cada perda de um emprego e local de trabalho acaba por in fluenciar diretamente o cotidiano da vida humana, de tal sorte que se pode partir da premissa de que a crise do Estado Social é, ao mesmo tempo, uma crise de toda a sociedade.

Oportunamente denominado de filho da moderna sociedade industrial, o Es tado Social de Direito não poderá jamais permanecer imune às suas transformações e desenvolvimento. ${ }^{2}$ Limitando-nos, por exemplo, a uma das manifestações da atuação do Estado Social e analisando a problemática dos sistemas de segurança social, verifica-se que é particularmente nesta esfera que o dilema representado pela simultânea necessidade de proteção e, por outro lado, de uma constante adequação dos níveis de segurança social vigentes à realidade sócio-econômica se manifesta com particular agudeza. Se, por um lado, a necessidade de uma adaptação dos sistemas de prestações sociais às exigências de um mundo em constante transformação não

pode ser desconsiderada, simultaneamente o clamor elementar da humanidade por segurança e justiça sociais continua a ser um dos principais desafios e tarefas do Estado. ${ }^{3}$

De outra parte, a crescente insegurança no âmbito da seguridade social decorre, neste contexto, de uma demanda cada vez maior por prestações sociais e de um paralelo decréscimo da capacidade prestacional do Estado e da sociedade. ${ }^{4} \mathrm{O}$ quadro delineado remete-nos, por outro lado, ao angustiante questionamento de o quanto as conquistas sociais podem e devem ser preservadas. Em que pese o entendimento dominante de que uma supressão pura e simples dos sistemas de seguridade social, sem qualquer tipo de compensação, não é, em princípio, admissível e sequer tem sido seriamente defendida, a problemática relativa à proteção constitucional das posições sociais existentes permanece no centro das atenções. ${ }^{5} \mathrm{Em}$ outras palavras, cuida-se de investigar se, como e em que medida os sistemas prestacionais existentes, concretizadores do princípio fundamental do Estado Social, podem ser assegurados contra uma supressão e/ou restrições.

Neste particular, é preciso ressaltar que, de acordo com a doutrina majoritária, uma proibição absoluta de retrocesso social tem sido excluída de plano, mormente em face da dinâmica do processo social e

2. C.. K.H. Friauf, in Sozialstaat - Idee und Entwicklung, Reformzwänge und Reformziele, p. 67.

3. Aeste respeito v. B. Schulte, in: ZIAS 1988, pp. 208 e ss.

4. Cl., entre outros, B. Schulte, in B. RiedmüllerM. Rodenstein (Org), Wie Sicher ist die soziale Sicherheit? (O quanto é segura a seguridade social?), pp. 323-4. Sobre as causas da crise v. também P. Rosanvallon, $A$ Crise do Estado-Providência, pp. 13 e ss.

5. Aeste respeito v. E. Eichenhofer, in ZIAS 1988, pp. 239 e ss. e, mais recentemente, O. Depenheuer, in $A O ̈ R n^{\Omega} 120$ (1995), pp. 417 ess. Na literatura em língua portuguesa encontramos, posicionando-se favoravelmente a uma vedação ao menos relativa de retrocesso na esfera social, especialmente J.J. Gomes Canotilho, Direito Constitucional e Teoria da Constituição, pp. 320 e ss.

Revista da Faculdade de Direito da UFRGS, v. 17, 1999 da indispensável flexibilidade das normas vigentes, de modo especial, com vistas à manutenção da capacidade de reação às mudanças na esfera social e econômica. ${ }^{6}$ Por outro lado, constata-se que a Lei Fundamental da Alemanha (no que não se encontra isolada no âmbito europeu) não contém nenhum preceito que direta e expressamente ofereça qualquer tipo de proteção ao nível constitucional do sistema de segurança social e dos níveis prestacionais vigentes, advogando-se, além disso, o entendimento de que tal garantia não pode ser direta e exclusivamente deduzida do princípio geral (fundamental) do Estado Social de Direito (arts. 20, inc. I e 28, inc. I, da LF) ou mesmo das diversas normas de competência. ${ }^{7}$ Mesmo assim, no âmbito de uma proibição relativa de retrocesso, a doutrina e a jurisprudência alemãs, confrontadas com o problema, lograram desenvol. ver, a partir do direito constitucional positivo, algumas alternativas destinadas a ensejar um certo grau de proteção às prestações sociais e ao sistema global de seguridade social. Particular relevância assumiu, neste contexto, o direito e garantia fundamental da propriedade (art. 14, da LF), razão pela qual esta será priorizada neste breve estudo sobre a proibição de retrocesso social na Alemanha. As demais alternativas referidas na doutrina serão, por ora, objeto de mera apresentação, tanto pelas limitações deste artigo, quanto pelo fato de que não lograram atingir a mesma importância.

Antes de iniciarmos a análise propriamente dita da função da garantia da pro. priedade para a proteção do sistema de seguridade social na Alemanha, convém lembrar o leitor de que, ao mesmo tempo em que a discussão em torno da redução (e até mesmo do desmonte completo) do Estado Social de Direito apresenta proporções mundiais, não há como desconsiderar que as dimensões da crise e as respostas reclamadas em cada Estado individualmente considerado são inexoravelmente diversas, ainda que se possam constatar pontos comuns. Diferenciadas são, por outro lado, as soluções encontradas por cada ordem jurídica para enfrentar o problema, diferenças que não se limitam à esfera da natureza dos instrumentos, mas que abrangem, de modo especial, a intensidade da proteção outorgada por estes aos sistemas de seguridade social.

estudo do modelo germânico, no âmbito do direito comparado, assume particular interesse por várias razões, destacando-se o fato de que a Alemanha foi não apenas o berço do socialismo científico de KARL MARX e FRIEDRICH ENGELS, mas também da social-democracia (com LASSALE), bem como da própria noção de um Estado Social e Democrático de Direito, bastando aqui a referência à Constituição de Weimar (1919), vertente do constitucionalismo social deste século. Por outro lado, pela posição de destaque que a Alemanha (juntamente com a França e a Itália, por exemplo) ocupa na União Euro-
6. Neste sentido, a lição de R.-U. Schlenker, Soziales Rückschrittsverbot und Grundgesetz, p. 239.

7. Cf. R.U. Schlenker, Soziales Rückschrittsverbot und Grundgesetz, pp. 240-1. 
péia, o estudo do exemplo germânico, além de expressar de modo geral e paradigmático - ressalvadas as especificidades de cada país - a realidade do Estado Social de Direito na Europa Ocidental, serve como importante fonte de referência para uma análise comparativa.

Além disso, a peculiaridade das soluções desenvolvidas pela doutrina e jurisprudência alemã, independentemente de sua eficácia e de suas vantagens, merece alguma atenção não apenas pelas alternativas oferecidas, mas também pelo uso de certas categorias que, salvo melhor juízo, poderiam gerar certo interesse prático também entre nós, notadamente no que diz com a figura da expectativa de direitos, a proteção da confiança e o uso do princípio da proporcionalidade. Ademais, assume relevo o uso alternativo do direito e garantia fundamental da propriedade, sinalizando de forma paradigmática as diversas funções que podem ser deduzidas dos direitos fundamentais e das transformações que estes sofreram ao longo dos tempos. Assim, ainda que venhamos a concluir pela desnecessidade ou inconveniência desta solução no âmbito do direito pátrio, de modo especial em face dos mecanismos consagrados em nos sa Constituição, temos a convicção de que o presente estudó não se restringe a um mero capricho pessoal, já que - salvo melhor juízo - o desmantelamento do Estado Social de Direito também entre nós se encontra na ordem do dia.
Por derradeiro, ainda no que diz com a apresentação do tema e as limitações des te estudo, cumpre ressaltar que a nossa atenção estará centrada na apresentação e breve análise do modelo germânico, de modo especial, na dimensão constitucional, isto é, jurídico-positiva, do problema da proibição de retrocesso social. Estamos cientes, todavia, de que estaremos nos ocupando apenas de um dos inúmeros aspectos da problemática global das possibilidades $\mathrm{e}$ limites do Estado de Direito, isto sem falar na relevância filosófica, sócio-econômica e política do tema.

\section{A garantia fundamental da propriedade e a proteção constitucional de posições jurídicas sociais prestacionais}

Consoante já referido, a principal solução desenvolvida na Alemanha para fundamentação de uma proteção para o sistema de prestações sociais e das respectivas posições jurídico-subjetivas encontra-se vinculada ao direito e garantia fundamental da propriedade (art. 14, da LF). A problemática da estabilidade e flexibilidade das posições jurídicas no âmbito da seguridade social acabou, por esta via, alcançando uma dimensão genuinamente constitucional ${ }^{8}$. Ainda que este tema continue sendo controverso, o Tribunal Federal Constitucional da Alemanha (Bundesverfassungsgericht), após uma fase inicial caracterizada por uma

8. Cf. O. Depenheuer, in $A O ̈ R n^{8} 120$ (1995), p. 419

certa retração, ${ }^{9}$ acabou por reconhecer em diversas decisões que a garantia da propriedade alcança também a proteção de posições jurídico-subjetivas de natureza pública de tal sorte que, atualmente, se pode falar da formação de um determinado grau de consenso nesta esfera. ${ }^{10}$

Como ponto de partida para este desenvolvimento, costuma referir-se a doutrina de MARTIN WOLFF, que relativamente ao art. 153 da Constituição de Weimar, advogava o ponto de vista de que o conceito de propriedade abrange toda sorte de direitos subjetivos privados de natureza patrimonial, o que acabou por levar à afirmação de um conceito funcionalista de propriedade ${ }^{11}$. Daí por que a garantia da propriedade não protege apenas a propriedade no âmbito dos direitos reais, mas al cança uma função conservadora de direitos, no sentido de que ela igualmente tem por escopo oferecer ao indivíduo segurança jurídica relativamente aos direitos patrimoniais reconhecidos pela ordem jurí dica, além de proteger a confiança deposi tada no conteúdo de seus direitos. ${ }^{12}$

As posições jurídico-subjetivas patrimoniais de natureza pública acabaram sendo colocados sob a proteção da garantia

9. Esta a observação, entre outros, de Rittstieg, in $A K I$, p. 1098

10. Cf. H.J. Papier, in Maunz/Herzog/Dürig/Scholz, art. 14, p. 77 .

11. Esta a liçăo de O. Depenheuer, in $A O ̈ R n^{2} 120$ (1995), p. 421

12. Cf. a lapidar formulação de P. Badura, in HbVR, p. 347.

13. Assim também P. Badura, in HbVR, p. 349.

14. Cf. BVerfGE 53,257 (290)

15. A este respeito e sobre as diversas etapas da evolução no âmbito da jurisprudência do Tribunal Federal Constitucional, v. W. Leisner, in HbStR VI, p. 1069 fundamental da propriedade, na medida em que se considerou que o princípio do Estado de Direito exige um tratamento igualitário relativamente às posições jurídico-subjetivas privadas. ${ }^{13}$ Para o Tribunal Federal Constitucional, o reconhecimento desta proteção outorgada às posições subjetivas de direito público por meio da garantia fundamental da propriedade encontra seu principal alicerce na estreita vinculação entre o direito de propriedade e a liberdade pessoal, no sentido de que ao indivídùo deve ser assegurado um espaço de liberdade na esfera patrimonial, de tal sorte que possa formatar de maneira autônoma sua existência. ${ }^{14}$

Ainda no que diz com a proteção de posições jurídico-subjetivas de natureza pública por meio da garantia fundamental da propriedade, o Tribunal Federal Constitucional, já em arestos anteriores, entendeu que esta proteção tem por pressuposto a circunstância de que ao titular do direito é atribuída uma posição jurídica equivalente à da propriedade privada e que, no caso de uma supressão sem qualquer compensação, ocorreria uma colisão frontal com o princípio do Estado de Direito, tal como plasmado na Lei Fundamental. ${ }^{15}$ Paradigmática é, portanto, 
a virtual equiparabilidade das posições subjetivas de direito público com a condição do proprietário. ${ }^{16}$ Com a inclusão de direitos subjetivos patrimoniais de natureza pública na esfera da seguridade social no âmbito de proteção da garantia fundamental da propriedade, verificou-se uma ampliação do conceito de propriedade vigente no direito privado, do qual o conceito constitucional de propriedade acabou por se desprender quase que completamente. ${ }^{17}$

De acordo com a melhor doutrina e jurisprudência, verifica-se, todavia, que nem todos os direitos subjetivos patrimoniais de natureza pública encontram-se abrangidos pela garantia fundamental da propriedade (art. 14, da LF), mas tão-somente os que atendem a determinados requisitos, sendo, desde logo, descartada uma extensão generalizada. ${ }^{18} \mathrm{~A}$ partir de duas decisões modelares sobre o tema, o Tribunal Federal Constitucional acabou enunciando alguns critérios essenciais para o reconhecimento da proteção de posições jurídico-subjetivas de natureza pública pela garantia da propriedade, quais sejam: a) à posição jurídica individual (isto é, ao direito subjetivo a prestação social) deve corresponder uma contraprestação pessoal de seu titular; b) deve tratar-se de uma posição jurídica de natureza patrimonial, que possa ser tida como de fruição privada para o seu titular; c) ela deve servir à garantia da existência de seu titular. ${ }^{19}$ Sobre estes pressupostos passaremos a nos manifestar em seguida.

No que diz com o primeiro critério, é preciso que se leve em conta se o direito subjetivo público se encontra exclusivamente fundado em uma prestação estatal ou se ele pode ser tido como equivalente a uma prestação própria de seu titular. ${ }^{20}$ Uma posição jurídico-subjetiva patrimonial embasada exclusivamente numa prestação unilateral do Estado tem sido rechaçada. ${ }^{21}$ O quanto cada titular de um direito público subjetivo deve ter contribuído a título de prestação própria ainda não foi, contudo, completamente esclarecido. ${ }^{22}$ No que tange a este aspecto, é possível partir da premissa de que uma equivalência absoluta entre a prestação estatal e a contrapartida pessoal não se revela como indispensável, bastando - de acordo com o Tribunal Federal Constitucional - uma contribuição "não irrelevante" por parte do titular do direito. ${ }^{23}$ Significativo é que, desde sua decisão do dia 16.07.1985, o Tribunal tem sustentado o entendimento de que, para o reconhecimen-

16. Cf. Bryde, in von Münch/Kunig, p. 840, e, mais recentemente, R. Wendt, in M. Sachs (Org), Grundgesetz, p. 491

17. Neste sentido a oportuna referência de Bryde, in von Münch/Kunig, p. 830 .

18. Ch., dentre outros, H.-J. Papier, in Maunz/Dürig/Herzog/Scholz, art, 14, p. 80 .

19. Ainda que $\mathrm{O}$ Tribunal tenha, posteriormente, adaptado e aprimorado certos aspectos específicos, as estruturas fundamentais de sua jurisprudência nesta seara foram preservadas. A este respeito v. O. Depenheuer, in $A O ̈ R n^{2} 120$ (1995), p. 423. 20. Ct. BVerfGE 53,257 (291).

21. Neste sentido, W. Boecken, Der verfassungsrechtliche Schutz, p. 71.

22. Cf. W. Leisner, in HbStR VI, p. 1069.

23. Cf. BVertGE $69,272(300)$.

to da proteção da garantia da propriedade, considera-se suficiente que a pretensão do particular não se encontre embasada única e exclusivamente numa prestação unilate ral do Estado. ${ }^{24}$

Para além disso, tem sido tolerado que a contraprestação provenha de terceiros, em favor do titular do direito, tal como ocorre com as contribuições sociais dos empregadores. ${ }^{25}$ Importa referir, neste con texto, o fato de que é a totalidade da pre tensão e não apenas as parcelas equivalentes às contrapartidas individuais dos particula res que se encontra abrangida pela prote ção da garantia da propriedade. ${ }^{26} \mathrm{Na}$ base do critério da contrapartida pessoal do particular, encontra-se a concepção de que as posições jurídicas patrimoniais de natureza pública radicam no reconhecimento do esforço pessoal, isto é, do que foi alcançado pelo trabalho e formação profissional de cada indivíduo, ${ }^{27}$ correspondendo, além dis so, à concepção de que é o próprio indiví duo que deve, em princípio, zelar pelo seu sustento. ${ }^{28}$ Ainda que o reconhecimento da proteção por meio da garantia da propriedade não esteja condicionado ao montante

da contraprestação pessoal (desde que esta exista e não seja irrelevante), este tem sido considerado decisivo quando se cuida de avaliar a relação de pertinência pessoal (der personale Bezug), no sentido de que quanto maior a contraprestação do particular, mais robusto o vínculo pessoal que caracteriza a proteção constitucional baseada no direitogarantia de propriedade. ${ }^{29}$ Assim, chega-se à conclusão de que para o Tribunal Federal Constitucional, o montante da contribuição pessoal é decisivo para o alcance e a definição da intensidade da proteção constitùcional das posições jurídico-subjetivas de natureza pública no âmbito da seguridade social. ${ }^{30}$

Estreitamente vinculada ao critério da contribuição pessoal do particular, situase a segunda condição exigida pelo Tribunal Federal Constitucional, qual seja a de que as posições jurídicas patrimoniais de direito público protegidas constitucionalmente correspondam, de certa forma, às posições jurídico-subjetivas particulares, sintonizando, de tal sorte, com a noção de propriedade particular. ${ }^{31}$ De acordo com o Tribunal, esta equivalência pode ser reco-

24. Cf. BVerfGE 69, 272 (301). Na doutrina, v. especialmente H.J. Papier, in Maunz/Dürig/Herzog/Scholz, art. 14, pp. 84-5, que oportunamente chama a atenção para o fato de que com esta decisão, o Tribunal acabou rechaçando a presunção de que a proteçăo constitucional das prestaç̄es sociais (notadamente das de cunho previdenciário) se limitaria, em verdade, a uma protecão do montante das contribuiçóes particulares, de tal sorte que acabou por se aceitar uma proteção generalizada dos direitos previdenciários (pensōes e aposentadorias).

25. Cf. BVerfGE 69, 272 (302).

26. Cf. O. Depenheuer, in $A O ̈ R n^{2} 120$ (1995), p. 425

27. Esta a formulaçáo de P. Badura, in HbVR, p. 350. Neste sentido v. também H.J. Papier, in Maunz/Dürig/Herzog/Scholz, art. 14, p. 81.

28. Cf. O. Depenheuer, in $A O ̈ R n^{8} 120$ (1995), p. 425 .

29. Cf. BVeríGE 53, 257 (292) e 58, 81 (112).

30. Esta a constatação de H.J. Papier, in_Maunz/Dürig/Herzog/Scholz, art. 14, p. 85

31. Neste sentido v. BVerfGE 69, 272 (300-1). 
nhecida quando o titular do direito pode partir da premissa de que se cuida de uma posição jurídica pessoal, própria e exclusi$\mathrm{va},{ }^{32}$ caracterizada por uma essencial disponibilidade por parte de seu titular. ${ }^{33}$ De outra parte, esta indispensável relação de similitude com o direito de propriedade, tal como exigida pelo Tribunal Federal Constitucional, pressupõe que estejamos diante de uma posição jurídico-subjetiva pessoal consolidada, que não poderá ser simplesmente suprimida de acordo com o que deflui do princípio do Estado de Direito. ${ }^{34}$

Essencial para o reconhecimento da proteção de uma posição jurídico-subjetiva na esfera da segurança social por meio da garantia da propriedade é, além disso, o fato de que deverá ser destinada à garantia da existência de seu titular. ${ }^{35}$ Com este entendimento, o Tribunal Federal Constitucional acabou aderindo à posição sustentada, no âmbito de decisão anterior, pela Juíza RUPPVON BRÜNNECK, em seu voto dissidente, de acordo com a qual quando a garantia da propriedade contém também um certo grau de proteção da liberdade, na medida em que assegura ao cidadão as condições necessárias para uma vida autônoma e responsável, assim também esta proteção de verá abranger as posições jurídico-subjetivas

de direito público, já que estas têm alcançado uma crescente importância para a pessoa no que diz com sua existência econômica. ${ }^{36}$

Cumpre observar, todavia, que com este critério adicional, o pressuposto da contraprestação do particular acabou sendo relativizado, ${ }^{37}$ já que com o caráter exis. tencial da posição jurídico-subjetiva individual, o Tribunal Federal Constitucional reconheceu que a maior parte dos cidadãos alcança a sua segurança existencial econômica (wirtschaftliche Existenzsicherung), menos por meio de patri-mônio privado imobiliário e/ou mobiliário, do que pelo resultado de seu trabalho. ${ }^{38}$ Para o Tribunal, a garantia da propriedade no Estado Social de Direito sofreria um sério déficit na sua funcionalidade, caso não abrangesse posições jurídico-subjetivas patrimoniais que cumprem a função de principal e, por vezes, até mesmo de única fonte para a existência de maior parte da população. ${ }^{39}$

No âmbito destes três pressupostos e da ampliação do conteúdo social do conceito de propriedade a eles vinculada, ${ }^{40}$ a proteção das posições jurídico-subjetivas patrimoniais de direito público pela garantia da propriedade foi sensivelmente

32. Assim também BVerfGE 69, 272 (300-1)

33. Neste sentido, v. W. Boecken, Der verfassungsrechtliche Schutz, p. 73.

34. Cf. R. Wendt, in M. Sachs (Org), Grundgesetz, p. 491.

35. C. BVerfGE 69, 272 (303).

36. Cf. BvertGE 32, 129 (142).

37. Cl. W. Leisner, in HbStR VI, p. 1070

38. Cf. BVerfGE 69, 272 (303)

39. Cf. BVerfGE 53,257 (294)

40. Cl. a oportuna referência de W. Leisner, in HbStR VI, p. 1070

Revista da Faculdade de Direito da UFRGS, v. 17, 1999

enrobustecida. Assim ocorre, por exemplo, com a maioria das prestações que integram o sistema público de seguridade social, de modo especial, contudo, as aposentadorias e pensões. ${ }^{41}$ Também as expectativas de direitos (Anwartschaften) foram abrangidas, notadamente aquelas posições jurídico-subjetivas de direito público que, mediante o implemento de outras condições (por exemplo um certo prazo de espera e/ou carência), tornam-se plenamente exigíveis. ${ }^{42} \mathrm{Da}$ mesma forma ocorre com o seguro-desemprego, os direitos decorrentes do seguro de acidentes, a remuneração pelo trabalho temporário (Kurzarbeitsgeld), os incentivos para a infância (Kinderzuschüsse), bem como com o seguro-saúde dos aposentados contra doenças, apenas para citar as hipóteses mais habituais. ${ }^{43}$ Não protegidas pela garantia de propriedade (art. 14, da LF), são, em contrapartida, as assim denominadas prestações reabilitatórias (Rehabiliationsleistungen) e secundárias (Nebenleistungen) sem a respectiva contraprestação ${ }^{44}$, tal como o auxílio para as crianças (Kindergeld), o auxílio para a juventude (Jugendhilfe), a assistência social (Sozialhilfe), o auxílio-moradia (Wohngeld), os incentivos para a formação profissional (Ausbildungsförderung) e a indenização social (soziale Entschädigung)..$^{45}$ Já que não se cuida, aqui, de relacionar todos os possíveis exemplos, analisando-os indi-

vidualmente, cumpre referir, neste contexto, que, para o reconhecimento da proteção constitucional ora em exame, é necessário que se trate de prestações obrigatórias (Pflichteleistungen), o que exclui, desde logo, prestações discricionárias, que não radicam numa posição jurídica similar à propriedade privada, ao menos, de acordo com o entendimento do Tribunal Fede. ral Constitucional e de parte da doutrina. ${ }^{46}$

Os critérios enunciados pelo Tribunal Federal Constitucional e, de regra, reconhecidos também pela doutrina, não ficaram, contudo, imunes à críticas. Neste sentido, costuma referir-se, a partir do paradigmático voto dissidente da JUÍZA RUPP-VON BRÜNNECK, que não se revela razoável o entendimento de que a proteção outorgada pela garantia fundamental da propriedade às posições jurídico-subjetivas patrimoniais de direito público deva, necessariamente, estar condicionada a uma contraprestação do titular do direito e, além disso, servir para garantir a sua existência. Argumenta-se, neste sentido, que estes dois requisitos não são aplicados no âmbito do direito privado, onde basta a existência de um direito subjetivo de cunho patrimonial, de tal sorte que os critérios da contraprestação e do caráter existencial - exigidos em se tratando de posições jurídico-prestacionais de natureza pública - assumiriam

41. Cf. Bryde, in von Münch/Kunig, p. 841

42. Neste sentido v. BVerfGE 53,257 (289-90)

43. Cf. R. Wendt, in M. Sachs (Org) Grundgesetz, p. 492, Jarass/Pieroth, p. 322, Rittstieg, in AKI, p. 1098 e H.-J. Papier, in_Maunz/ Dürig/Herzog/Scholz, art. 14, p. 95.

44. Ct. R. Wendt, in M. Sachs (Org) Grundgesetz, p. 492

45. Ct. H-J. Papier, in Maunz/Dürig/Herzog/Scholz, art. 14, p. 94.

46. Assim também H.J. Papier, in Maunz/Dürig/Herzog/Scholz, art. 14, p.95. 
relevância apenas no que diz com a problemática dos limites à regulamentação legislativa. ${ }^{47}$

Aderindo a estas críticas, o Prof. HANS-JÜRGEN PAPIER, da Universidade de Munique, ressalta o fato de que as posições patrimoniais jurídico-privadas alcançam sua força direta e exclusivamente a partir da norma contida no art. 14 , da LF (garantia da propriedade), de tal sorte que, se as posições de direito público já obtiveram sua especial força jurídica a partir de outras normas constitucionais, a aplicação supletiva da garantia da propriedade não apenas se revela desnecessária, mas relativizante, visto que, de acordo com o art. 14, inc. III, da LF, estaria, em princípio, sujeita a ser desapropriada mediante uma indenização.

Neste contexto, há, ainda, quem advirta para os riscos de uma ruptura no clássico e unitário conceito de propriedade, no sentido de que estaria ocorrendo uma inequívoca evolução de uma propriedade assegurada sem reservas, para uma propriedade carente de justificação (rechtfertigunsbedürftigten Eigentum)" ${ }^{48}$ Para além disso, argumenta-se que o requisito da

garantia existencial (Existenzsicherung) acabaria levando a uma tendencial substituição do conteúdo liberal da garantia da propriedade. ${ }^{49}$ No que diz com a exigência da contraprestação do titular do direito, sustenta-se a opinião de que no âmbito dos direitos patrimoniais públicos não se cuida do direito a uma parcela do patrimônio global da seguridade social equivalente à soma das contraprestações pessoais do titular, mas sim, da participação na receita futura da previdência social, de tal sorte que à pretensão do particular corresponde apenas de forma relativa e em tese uma contrapartida pessoal equivalente. ${ }^{50}$

Por derradeiro, aponta-se oportunamente para a circunstância de que, em decorrência dessa flexibilização e ampliação da noção de propriedade e do âmbito de proteção da respectiva garantia fundamental, corre-se o risco de uma crescente relativização desta proteção, visto que em virtude das exigências da função social da propriedade, boa parte daquilo que foi concedido poderá acabar sendo retirado. ${ }^{51} \mathrm{Com}$ efeito, no âmbito do já referido dilema representado pela necessidade constante de adaptação e simultânea proteção dos níveis prestacionais vigentes, a problemática $\mathrm{da}$

47. Assim, aproximadamente, Rittstieg, in AK I, p. 1099. Neste sentido v. também a crítca de H.-J. Papier, in Maunz/Dürig/Herzog/ Scholz, art. 14, p. 81, que, para além da critica já tecida, chama a atençăo para o fato de que as posiçōes jurídico-patrimoniais privadas alcançam sua força única e exclusivamente com base no art. $14 \mathrm{da} L F$, de tal sorte que se as posiçōes de direito público á obtiveram sua especial força jurídica a partir de outras normas constitucionais, a aplicação supletiva do art. 14 da LF não se revela apenas desnecessária, mas relativizante, visto que, de acordo com o disposto no art. 14, inc. III, da LF, estaria sujeita a ser desapropriada mediante uma indenizaçăo. (Entziehbar).

48. Neste sentido, a pertinente preocupaçăo de O. Depenheuer, in $A O ̈ R n^{8} 120$ (1995), p. 428

49. Cf. O. Depenheuer, in $A O ̈ R n^{2} 120$ (1995), p. 434.

50. Cf. O. Depenheuer, in $A O ̈ R n^{\ell} 120$ (1995), pp. 429-31, o qual questiona o critério da contraprestação pessoal do particular, reconhecendo-the - com exceção de sua utilidade como criterio de cálculo (Berechnungsfaktor) - apenas uma reduzida significação.

51. Neste sentido v. também O. Depenheuer, in AÖR $n^{2} 120$ (1995), pp. 434 e ss. Assim também W. Leisner, in HbStR VI, p. 1071, que também fala do perigo de uma diluição do conceito de propriedade ("Verwässerung des Eigentums"). cimentização das posições jurídicas sociais acaba por alcançar dimensões preocu pantes, de modo especial em face da possibilidade de restrições por parte do legislador, expressamente autorizadas pelo art. 14 , inc. I, da Lei Fundamental, bem como do conseqüente risco de uma flexibilização demasiada da proteção constitucional da propriedade, já referida. Importa consignar, neste sentido, que a proteção concreta das posições jurídicas sociais depende, em última análise, da definição do conteúdo e dos limites da garantia fundamental da propriedade por parte do legislador. ${ }^{52}$

A respeito deste tema, cumpre ainda citar o entendimento do Tribunal Federal Constitucional, para o qual, "na determinação do conteúdo e dos limites de posições jurídicas previdenciárias, o legislador dispõe de uma ampla liberdade de conformação. Isto aplica-se principalmente à normas que se destinam a preservar, aperfeiçoar ou adaptar à realidade econômica em mutação, em benefício da coletividade, a funcionalidade e capacidade prestacional do sistema legal de previdência social. Neste sentido, a norma contida no art. 14 , inc I, da Lei Fundamental também abrange a possibilidade de restringir direitos e expectativas de direitos. Conquanto tal medida sirva ao interesse comunitário e corresponda ao princípio da proporcionalidade, ao legislador não estará, em princípio, vedada a re- dução de prestações, bem como a alteração da amplitude de pretensões e expectativas, assim como a sua adequação. Todavia, sua liberdade de atuação encontra-se reduzida, na mesma proporção em que os direitos e expectativas estão impregnados pelo vínculo pessoal da contrapartida de seu titular". ${ }^{53}$

A partir destas considerações do Tribunal Federal Constitucional, constata-se que quanto maior a função social da posição jurídica prestacional protegida e existindo uma justificativa legitimadora, no caso, o interesse coletivo, tanto maior é a possibilidade de restrições por parte do legislador. Em contrapartida, o caráter existencial da posição jurídica e o montante da participação do titular traçam limites mais ou menos severos a esta atividade legislativa. De qualquer modo, é preciso considerar sempre a proporcionalidade da medida restritiva e o respeito ao princípio da proteção da confiança. ${ }^{54}$ Uma restrição será constitucionalmente legítima - de acordo com o Tribunal Constitucional - quando a limitação, adequação ou reformulação das posições jurídicas prestacionais se revela como indispensável para a proteção da capacidade funcional e prestacional do sistema de seguridade social. ${ }^{55}$ Além disso, deverão ser observados os pressupostos específicos do princípio da proibição de excesso (Ubermassverbot), notadamente, que a medida restritiva seja necessária e adequada ao

Revista da Faculdade de Direito da UFRGS, v. 17, 1999

Revista da Faculdade de Direito da UFRGS, v. 17, 1999

52. Cf. W. Boecken, Der Verfassungsrechtliche Schutz, p. 74, em adesão à jurisprudência da Corte Federal Constitucional (BVerfGE 53,257 [292]).

53. Cf. BVerfGE 53, 257 (293), posteriormente confirmado em BVerfGE 58, 81 (122 e ss.) e BVeriGE 69, 272 (304).

54. A este respeito V. especialmente H.-J. Papier, in Maunz/Dürig/Herzog/Scholz, art. 14, p. 85, bem como W. Boecken, Der verfassungsrechtliche Schutz, pp. 77-8.

55. Cf. BVerfGE 53, 257 (296) e BVerfGE 58, 81 (114). 

Por outro lado, a restrição dependerá de dispensável à preservação de bens jurídicos fim almejado pelo legislador, não podendo, para além disso, ser excessivamente onerosa (Belastend) e inexigível (Unzumutbar) Assim, constata-se a indispensabilidade de uma ponderação que leve em conta a rela ção de equilíbrio entre a intensidade da restrição para o titular do direito e os valores utilizados para legitimar a restrição. ${ }^{56}$

Ainda no que diz com a legitimidade de eventuais medidas restritivas, há que considerar que a aferição da propor cionalidade da restrição poderá ser realizada apenas à luz do caso concreto, já que a resposta depende da comparação entre o interesse público na restrição e o interesse individual do titular do direito na sua preservação, não podendo, portanto, ser préestabelecida de forma genérica e abstrata. ${ }^{57}$ especial justificação constitucional quando o legislador invadir o núcleo essencial da equivalência pessoal, já que neste caso não basta a existência de qualquer fim coletivo. A restrição deverá servir, portanto, à proteção de outros direitos fundamentais, ser insuperiores ou mesmo atuar como mecanismo de defesa contra graves ameaças, devidamente comprovadas ou pelo menos altamente prováveis. ${ }^{58}$

A estes pressupostos soma-se a necessidade de se atentar para o princípio da proteção da confiança, por sua vez, diretamente vinculado ao Estado de Direito, o qual, relativamente à garantia fundamental da propriedade do art. 14 da Lei Fundamental, realiza a função de uma garantia da segurança jurídica para o cidadão. ${ }^{59}$ Isto assume relevância especialmente nos casos em que a medida legislativa restritiva acaba atingindo direitos adquiridos. Ainda que os titulares não tenham direito a uma determinada posição legislativa (Gesetzeslage), vindo a ser atingidas posições jurídicas já consolidadas, o interesse individual deverá ser especialmente considerado, exigindo-se uma cuidadosa ponderação entre os objetivos do legislador e a necessidade de se proteger a confiança do particular. ${ }^{60}$ No contexto desta averiguação da proteção da confiança, a jurisprudência constitucional previu a necessidade de o legislador estabelecer regras razoáveis de transição, já que os atingidos pelas medidas restritivas deverão contar com a possibilidade de se adaptar à sua nova situação jurídica. ${ }^{61}$

Paralelamente ao princípio da prote. ção da confiança também tem sido sustentada a obrigação de continuidade do legislador na esfera social, inerente ao prin-

56. Neste sentido, v. W. Boecken, Der verfassungsrechtliche Schutz, pp. 77-8. Na jurisprudência, v. BVerfGE 58, 81 (114).

57. A este respeito v. D. Katzenstein, in FS für H. Simon, p. 860.

58. Esta a lição de H.J. Papier, in Maunz/Dürig/Herzog/Scholz, art. 14, pp. 85-6.

59. Neste sentido, v. W. Boecken, Der verfassungsrechtliche Schutz, pp. 78 e ss. Assim também D. Katzenstein, in FS für H. Simon, pp. 861 e ss. e BVerfGE 58,81 (120-1).

60. Assim o entendimento de D. Katzenstein, in FS für H. Simon, p. 863 e Rittstieg, in AKI, p. 1118.

61. V. os votos dissidentes dos Juizes E. Benda e D. Katzenstein em BVerfGE 58,81 (131 e ss.) e 72, 9 (23 ess.), onde a duplicação do prazo de carência no âmbito do seguro desemprego foi tida como inexigivel. Na literatura, $v$, entre outros, Rittstieg, in.AKI, p. 1118 .

Revista da Faculdade de Direito da UFRGS, v. 17, 1999 cípio do Estado de Direito, conjugada com a função substitutiva de remuneração (Lohnersatzfunktion) das aposentadorias. Neste sentido, advoga-se o ponto de vista de que as prestações na seara da previdência social devem respeitar o parâmetro resegurados em atividade profissional, o que decorre da obrigação de continuidade do legislador, que deverá zelar por uma certa continuidade sistêmica (Systemkontinuität) em favor do contribuinte, garantia que não se limita ao patamar representado pelas condições materiais mínimas para uma existência digna. ${ }^{62}$

Ainda no que concerne à proteção das posições jurídicas patrimoniais de direito público pela garantia da propriedade, cumpre referir o cunho participativo da norma contida no art. 14 da LF, no sentido de que as pretensões e expectativas individuais, na verdade, objetivam uma futura e relativa participação no resultado financeiro, na proporção das contribuições pessoais. ${ }^{63}$ Cuida-se, portanto, de uma garantia (fundamental) da participação individual no sistema global de seguridade e previdência social na medida das anteriores contribuições pessoais, de tal sorte que o titular da

posição jurídica não dispõe de uma pretensão a um valor determinado ou determinável da prestação social que possa ser tido como equivalente às contribuições pessoais. ${ }^{64}$

Do exposto, constata-se que a garantia fundamental da propriedade, no âmbito das prestações sociais, não assegura o nível prestacional vigente, razão pela qual o valor da prestação se encontra, relativamente às contribuições pessoais, tão-somente numa proporção relativa.$^{65}$ As contribuições do titular do direito servem, em última análise, para assegurar a posição no ranking da comunidade solidária dos assegurados sociais. ${ }^{66}$ Neste contexto, a doutrina chegou a referir uma espécie de transmutação (Wandelung) no âmbito da garantia fundamental da propriedade, que, de acordo com este entendimento, teria transitado de um direito de defesa para a condição de um direito de participação (quota-parte), o qual, por sua vez, se caracteriza pela sua dependência da capacidade prestacional do sistema global de seguridade social, trazendo consigo, todavia, o risco de uma relativização da proteção outorgada pelo art. 14 da Lei Fundamental (direito e garantia da propriedade). ${ }^{67}$ presentado pelo nível de rendimentos dos

62. Cf., de modo especial, H.J. Papier, in Maunz/Dürig/Herzog/Scholz, art. 14, pp. 88-9, que, baseado na liçăo de Scholz, aponta para o fato de que no âmbito desta obrigação de continuidade, não se assegura a aposentadoria calculada com bade no parâmetro da remuneração bruta, assim como não se garante o nível prestacional vigente, já que, no caso de uma queda na arrecadação, também uma diminuiçăo do valor das prestaçōes sociais se afigura possivel.

63. Neste sentido, v. O. Depenheuer, in $A O ̈ R n^{8} 120$ (1995), p. 442. Semelhantemente também P. Badura, in $H b V R_{2}$ p. 350, que igualmente sustenta a opiniāo de que as pretensőes e expectativas de direitos podem ser consideradas a partir de uma dimensão participativa da noção de propriedade (teilhaberechtlich ausgestaltetes Eigentum).

64. Cf. O. Depenheuer, in $A O O R n^{2} 120$ (1995), p. 442.

65. Cf. O Depenheuer, in $A O ̈ R n^{2} 120$ (1995), p. 442, assim como Rittstieg, in $A K I$, p. 1099. No åmbito da jurisprudência constitucional, v. BVerfGE 58,81 (108 e ss.).

66. Cf. O. Depenheuer, in $A O ̈ R n^{2} 120$ (1995), p. 442.

67. Neste sentido, principalmente, H.J. Papier, in.Maunz/Dürig/Herzog/Scholz, art. 14, p. 80, secundado por O. Depenheuer, in AÖR 
Por derradeiro, poderá concluir-se que, por meio da garantia fundamental da propriedade, as posições jurídicoprestacionais sociais acabaram recebendo uma proteção muito relativa e flexível, já que - de acordo com a precisa e oportuna formulação de Depenheuer - assegurada constitucionalmente é tão-somente a inespecífica pretensão à segurança existencial por meio de prestações sociais na esfera da seguridade e previdência social. ${ }^{68}$ Constata-se, portanto, que, se por um lado, a garantia de determinadas posições jurídicas sociais de direito público pode ser tida como segura, por outro, o que e o quanto é assegurado permanece inseguro.

\section{Outras possibilidades de proteção constitucional das posições jurídicas sociais de direito público: uma visão panorâmica}

Além da proteção por meio da garan tia fundamental da propriedade, existem evidentemente outras possibilidades de as. segurar constitucionalmente as posições jurídico-subjetivas prestacionais de direito público no direito alemão. Isto aplica-se principalmente às posições jurídicas que não preenchem as condições exigidas para a incidência do art. 14, inc. II, da Lei Fundamental. É de se atentar, por outro lado, que

não se trata de mecanismos assecuratórios complementares, mas de critérios autônomos constitucionalmente embasados. A doutrina, assim como a jurisprudência, costumam referir basicamente as seguintes alternativas: a) o princípio da proteção da confiança, desenvolvido a partir do postulado do Estado de Direito (art. 20, inc. III da LF); b) o princípio fundamental da dig. nidade da pessoa humana (art. $1^{\circ}$, inc. I, da LF); c) o princípio do Estado Social (art. 20 , inc. I, da LF); d) o princípio geral de igualdade (art. 3o, inc. I, da LF). É a respeito de tais alternativas que passaremos a tecer algumas considerações individualizadas, ainda que de cunho sumário.

A) No que diz com a importância do princípio (fundamental) da proteção da confiança, diretamente deduzido do princípio do Estado de Direito, este - de acordo com o entendimento majoritário na doutrina alemã - apenas alcança significado autônomo para a problemática da proteção das posições jurídicas sociais, na medida em que estas não se encontram abrangidas pelo âmbito de proteção da garantia da propriedade.$^{69}$ Como concretização do princípio da segurança jurídica, o princípio da proteção da confiança serve como fundamentação para a limitação de leis retroativas, que agridem situações fáticas já consolidadas (retroatividade própria), ou que atingem situações fáticas atuais, acabando, contu-

$n^{2} 120$ (1995), pp. 442-3. Averbe-se, todavia, a posiçăo crítica de G. Haverkate, in ZRP 1984, p. 221, que rechaça o cunho prestacional da garantia da propriedade, sob $o$ argumento de que, em verdade, nấo é o Estado que fornece as prestaços, sim, os contribuintes da seguridade social, de tal sorte que não é propriamente às prestaçes estatais que é outorgada dignidade dos direitos fundamentais, mas sim à comunidade dos segurados sociais. 68. Cf. O. Depenheuer, in $A O ̈ R n^{8} 120$ (1995), p. 444.

69. Neste sentido, entre outros, W. Boecken, Der verfassungsrechtliche Schutz, p. 81 e Bryde, in vón Münch/Kunig, p. 842. do, por restringir posições jurídicas geradas no passado (retroatividade imprópria), já que a idéia de segurança jurídica pressupõe a confiança na estabilidade de uma situação legal atual. ${ }^{70}$ Com base no princípio da proteção da confiança, eventual intervenção restritiva no âmbito de posições jurídicas sociais, exige uma ponderação entre a agressão (dano) provocada pela lei restritiva à confiança individual e a importância do objetivo almejado pelo legislador para o bem da coletividade. ${ }^{71}$

B) Vinculado ao princípio da proteção da dignidade da pessoa humana, tal como plasmado no art. $1^{\circ}$, inc. I, da LF, também pode ser tida como limite ao retrocesso na esfera da legislação social a preservação de um mínimo indispensável para uma existência digna, no sentido de que as restrições no âmbito das prestações sociais não podem, em hipótese alguma, ficar aquém deste limite, pena de ofensa ao princípio da dignidade da pessoa humana. Independentemente disto, há que considerar que - de acordo com a doutrina e a jurisprudência - a própria cláusula geral do Estado Social (art. 20, inc. I, da LF) já fundamenta uma obrigação do poder público no sentido de promover a assistência aos necessitados. ${ }^{72}$ Foi justamente neste contexto que a doutrina e jurisprudência alemãs desenvolveram, a partir de uma exegese criativa calcada na interligação entre o princípio da dignidade da pessoa humana (art. $1^{\circ}$, inc. I), do direito à vida (art. $2^{\circ}$, inc. I) e do princípio do Estado Social (art. 20, inc. I), um direito fundamental não escrito à garantia das condições materiais mínimas para uma existência digna. ${ }^{73}$

Somente isto já poderia servir de limite para uma legislação restritiva e, principalmente, demolitória do sistema de prestações sociais vigente, no sentido de que em qualquer hipótese jamais poderá o legislador agredir o núcleo essencial deste direito fundamental não escrito (ou implícito). Cumpre averbar, de outra parte, que a função social da garantia de uma existência digna já vem sendo concretizada, na Alemanha, há cerca de trinta e sete anos, no âmbito da legislação social infraconstitucional. ${ }^{74}$ Todavia, há que levar em consideração o fato de que na doutrina - muito embora não sem divergências - sustenta-se a opinião de que a assistência social prestada para uma garantia das condições mínimas existenciais não se limita ao mínimo no sentido econômico, alcançando também um mínimo na acepção sócio-cultural, ainda que a determinação do valor da prestação assecuratória deste mínimo existencial não tenha sido consensualmente obtida,

70. C. W. Boecken, Der verfassungsrechtliche Schutz, p. 80 .

71. Esta a lição de D. Katzenstein, in FS für H. Simon, p. 862, com apoio na jurisprudência do Tribunal Federal Constitucional, de modo especial, BVerfGE 64, 87 (104). Assim também W. Boecken, Der verfassungsrechtliche Schutz, p, 82 Cf., entre outros, o entendimento de H.F. Zacher, in HbStR L. pp. 1062 e ss.

73. Aeste respeito v. meu $A$ Eficácia dos Direitos Fundamentais, pp. $283 \mathrm{e} \mathrm{ss.}$

74. Basta, neste sentido, referir $0 \$ 9^{2}$ da Parte Geral do Código da Previdência e Seguridade Social (Sozialgesetzbuch - allgemeiner Teil), bem como dos $\$ 1^{2}$, inc. I, $4^{2}$, inc. I e 11, inc. I, da Lei Federal de Assistência Social (Bundessozialhilfegesetz), que, na sua formulação original, foi editada em 30.06 .1961 . 
não se podendo falar, até o presente momento, de uma solução uniforme no que diz com este aspecto. ${ }^{75}$

C) Também o princípio do Estado Social (art. 20, inc. I, da LF) costuma ser utilizado como fundamento para uma proteção constitucional de posições jurídicas sociais, ainda que neste contexto não lhe seja outorgada significação autônoma, já que a partir do princípio do Estado Social não se podem deduzir direitos subjetivos individuais a prestações legislativas determinadas, de tal sorte que o princípio apenas (o que não é pouco) fornece, como critério hermenêutico, diretrizes para a avaliação da constitucionalidade de restrições legislativas na esfera dos sistemas prestacionais vigentes. ${ }^{76} \mathrm{~A}$ importância do princípio do Estado Social manifesta-se, portanto, principalmente na sua combinação com outros valores constitucionais es. senciais consagrados pela Lei Fundamental, notadamente com o princípio da isonomia (art. 3ㅇ, inc. I), a garantia das condições existenciais mínimas (aqui, como já referido, em combinação com os arts. $1^{\circ}$, inc. I e 2 , inc. I), bem como com a concepção já referida atribuída à garantia fundamental da propriedade, impregnada do conteúdo de justiça social inerente ao princípio do Estado Social e Democrático de Direito.
D) Por derradeiro, também ao princípio geral de isonomia (art. 3으, inc. I, da LF) poderá ser atribuída uma importância relativamente limitada no que diz com a problemática da proibição de retrocesso social na Alemanha, isto pelo fato de que o princípio isonômico basicamente é utilizado como parâmetro para a aferição da constitucionalidade de medidas legislativas que dizem respeito a outro grupo de pessoas. ${ }^{77}$ Neste sentido, é necessário que, na hipótese de uma intervenção legislativa em posições jurídicas vigentes, a restrição resultante para todos os segurados (considerados individualmente ou em grupos) seja compatível com as exigências do princípio da igualdade, de tal sorte que este, atuando como mandado de uma restrição igualitária, cumpre a função de claro limite para a arbitrária tomada de medidas restritivas ou impositivas de encargos, de modo especial por parte do legislador. ${ }^{78}$

\section{Considerações finais, inclusive em nível de direito comparado}

Os exemplos referidos, de modo especial, a proteção das posições jurídicas so ciais de direito público pela garantia fundamental da propriedade, revelam que - para além de uma abolição pura e sim-

75. A respeito desta problemática v., entre outros, J. van Bargen, in FS für H. Simon, pp. 745 e ss. (de modo especial, porém, pp. 749 e ss.).

76. Cf. W. Boecken, Der verfassungsrechtliche Schutz, pp. 82-3.

77. Cf. W. Boecken, Der verfassungsrechtliche Schutz, p. 83.

78. Neste sentido v. a lição de B. Schulte, in ZIAS 1988, pp. 212-3, que ainda chama a atenção para o fato de que os efeitos do princípio da igualdade são, neste contexto, essencialmente de ordem negativa, no sentido de que ela veda determinadas configuraç̄os discriminatórias no âmbito da legislação social. Assim também, inobstante de forma mais timida, E. Eichenhofer, in ZIAS 1988, p. 240.

Revista da Faculdade de Direito da UFRGS, v. 17, 1999

ples, sem compensação, de sistemas prestacionais legais, a qual se encontra absolutamente vedada - também medidas de cunho restritivo somente podem ser toleradas até certo ponto, pena de eventual ofensa aos postulados básicos inerentes ao princípio do Estado Social de Direito e aos direitos fundamentais. Neste sentido, constatou-se que no âmbito do direito germânico é possível sustentar a existência de uma proteção constitucional dos direitos sociais previstos na legislação infraconstitucional, proteção cujo alcance não pode ser estabelecido previamente de forma genérica e abstrata. Isto porque esta proteção depende, por um lado, de uma cautelosa e criteriosa ponderação das circunstâncias concretas, devendo, de outra parte, levar em consideração o abismo inevitável entre a realidade fática e a dimensão normativa.

Para além disso, percebe-se que os critérios e alternativas desenvolvidos no âmbito do direito constitucional germânico podem ser trasladados apenas parcialmente para o direito pátrio, carecendo, ademais, de uma adaptação às especifitudes de nossa ordem jurídica. Por outro lado, existem aspectos comuns que não podem ser desconsiderados, de modo especial, o fato de que também entre nós não há como sustentar uma vedação absoluta de medidas restritivas na esfera dos direitos sociais prestacionais, já que nem mesmo os direitos fundamentais sociais expressamente consagrados na Constituição - os quais integram inequivocamente o rol das "cláusu- las pétreas" do art. $60, \S 4^{\circ}$, da CF de 1988 - são imunes a restrições. Com efeito, apenas a abolição efetiva ou tendencial destes direitos encontra-se vedada, uma vez que o que se pretende é a preservação de seu núcleo essencial, pena de uma indesejável galvanização das normas constitucionais, que, por seu turno, traz em seu bojo o risco de uma intolerável ruptura da ordem cons. titucional, em face do insuperável abismo entre a constituição formal e a realidade constitucional. ${ }^{79}$

Sendo comum a ambas as ordens jurídicas (alemã e brasileira) uma vedação pelo menos relativa de retrocesso na esfera do sistema vigente de prestações sociais, que, em última análise, representa a concretização no plano da legislação infraconstitucional do princípio do Estado Social de Direito e/ou dos direitos fundamentais sociais consagrados na Constituição, não há como negar, de outra parte, a existência de uma série de diferenças a serem consideradas.

Sem qualquer pretensão de exaurir a problemática, em face dos estreitos limites deste estudo, cumpre relembrar, num primeiro momento, o fato de que a Lei Fundamental da Alemanha não consagrou, como regra geral, direitos fundamentais sociais em seu texto, limitando-se a agasalhar o princípio fundamental do Estado Social e Democrático de Direito, a partir do qual foi desenvolvida uma abrangente e eficiente legislação na esfera da previdência e da

79. A respeito do significado do abismo entre norma e realidade constitucional e as suas consequêencias no âmbito da éetividade das normas constitucionais v. especialmente K. Hesse, A Força Normativa da Constituiçăo. Sobre a amplitude e alcance da proteçăo outorgada pelas assim denominadas "cláusulas pétreas" da Constituiçăo v. meu A Eficácia dos Direitos Fundamentais, pp. $359 \mathrm{e}$ 
seguridade social. Assim, os direitos a prestações sociais, ainda que indiretamente fundados na cláusula geral do Estado Social, têm embasamento legal, ressalvado o desenvolvimento jurisprudencial de direitos fundamentais sociais não escritos, como, de modo especial, a garantia das condições mínimas para uma existência digna, o direito à saúde e o direito à educação.

Justamente por este motivo, quando se fala na proibição de retrocesso social no caso da Alemanha, cuida-se principalmente da problemática da proteção das posições prestacionais consagradas em nível infraconstitucional. Para outorgar-lhes uma proteção constitucional, por estar em jogo a concretização do princípio do Estado Social, o qual também na Alemanha integra o elenco das "cláusulas pétreas", assim como em face da inexistência de normas expressas na Lei Fundamental assegurando uma proteção constitucional direta, as posições jurídico-prestacionais sociais de direito público acabaram sendo consideradas como abrangidas pela garantia fundamental da propriedade.

No sistema pátrio, pelo contrário, no qual a Constituição de 1988 foi pródiga em direitos fundamentais sociais, a problemática alcança um significado diverso, na medida em que o próprio "status" constitucional, de modo especial a fundamentalidade material e formal que caracteriza os direitos sociais, já assegura aos mesmos um grau diferenciado e, evidentemente, mais elevado de proteção, ainda que, lamentavelmente, não faltem os que impugnam não apenas a condição de "cláusula pétrea" dos direitos fundamentais sociais, mas até mesmo a sua fundamentalidade, ao menos no aspecto material.

Além disso, a existência de dispositivos expressos na nossa Constituição consagrando, em última análise, o princípio da proteção da confiança, demonstra que a construção alemã no que diz com a utilização do direito e garantia da propriedade, é - ao menos entre nós - desnecessária. Neste sentido, basta apontar para o que dispõe o art. 5, inc. XXXVI, da nossa Constituição, estabelecendo o respeito ao direito adquirido, ao ato jurídico perfeito e à coisa julgada, dispositivos que se aplicam principalmente (mas não exclusivamente) às posições jurídicas infraconstitucionais. Mesmo assim, temos a convicção de que algumas lições úteis podem ser extraídas do exemplo germânico.

Dadas as especifitudes do modelo pátrio, também entre nós há como sustentar a existência de uma proibição de retrocesso na esfera social, vedação que, todavia, não poderá jamais assumir feições absolutas. Esta proibição relativa de retrocesso, tendo em vista a previsão expressa de direitos sociais na nossa Constituição e a sua proteção por meio das "cláusulas pétreas" é, pelo menos do ponto de vista jurídiconormativo, mais robusta que as soluções desenvolvidas à luz da Lei Fundamental da Alemanha, carente de direitos fundamentais sociais e de norma expressa consagrando o respeito aos direitos adquiridos.

Outro aspecto que merece ser destacado é o fato de que a amplitude e intensidade da proteção outorgada pela ordem constitucional às posições jurídico-subjetivas na esfera social, tanto no plano consti- tucional, quanto ao nível da legislação ordinária, dependem de uma análise centrada nas especificidades do caso concreto, exigindo um procedimento tópico-sistemático, já que nos parece inviável o estabelecimento de critérios abstratos e genéricos, a não ser o próprio reconhecimento de uma proibição meramente relativa de retrocesso.

A importância do princípio da proteção da confiança que, ao menos no caso da Alemanha, exerce uma função semelhante à atribuída ao direito adquirido, revela, entre outros aspectos, o grave equívoco no qual incorrem aqueles que, objetivando fundamentar o livre avanço sobre as conquistas na esfera social, reportam-se ao argumento de que na maior parte dos países desenvolvidos inexiste proteção dos direitos adquiridos. Com efeito, impende considerar que, mesmo em ordens constitucionais em que os direitos adquiridos não mereceram expressa previsão e proteção pelo Constituinte, acabaram sendo objetos de proteção constitucional por meio do princípio (implícito) da proteção da confiança. Parece-nos que só esta constatação demonstra claramente que a opção pela abordagem do problema proposto neste estudo não se restringe a um mero capricho pessoal. Pelo contrário, evidencia de forma escancarada que a figura jurídica dos direitos adquiridos, respeitadas as especifitudes de cada ordem jurídica, ainda que não expressamente agasalhada na nossa Constituição, não prescin- de de um certo grau de proteção, já que (também entre nós) pelo menos implícita e indiretamente fundada no princípio do Es. tado de Direito.

Também pode ser tida como paradigmática a utilização do princípio da proporcionalidade como critério aferidor da legitimidade de uma restrição na esfera de uma proibição de retrocesso social, revelando, neste contexto, que a função do referido princípio, igualmente deduzido do princípio do Estado de Direito, não se limita a servir de parâmetro para o exame da constitucionalidade das leis restritivas de direitos fundamentais, incluídos neste rol os assim denominados direitos sociais. Com efeito, também a ação erosiva do legislador que tenha por objetivo a implementação de ajustes e cortes no âmbito do sistema infraconstitucional de prestações sociais deve levar em conta as exigências do princípio da proporcionalidade, isto é, ser ao mesmo tempo necessária, adequada e razoável, pena de ofensa aos próprios direitos fundamentais sociais e ao princípio do Estado Social de Direito. ${ }^{80}$ Em última análise, não se poderá abdicar jamais da tarefa de realizar uma cuidadosa ponderação de todas as circunstâncias, de modo especial entre o valor dos direitos dos particulares a determinado grau de segurança social e os reclamos do interesse da coletividade.

A sistemática adotada pela doutrina e jurisprudência constitucional alemãs, 
notadamente no que diz com o uso do direito e garantia fundamental da propriedade, revelam, por sua vez, de forma contundente, a multifuncionalidade carac terística dos direitos fundamentais em geral, assim como as transformações pelas quais têm passado. Além de reforçar, ainda que em outro contexto, a sua função social a ampliação do âmbito de proteção da garantia da propriedade, objetivando assegurar, ao menos de forma relativa, o conteúdo das posições jurídico-subjetivas sociais, especialmente de cunho prestacional, coloca em destaque a importância de uma hermenêutica constitucional criativa num mundo em constante transformação.

Pela sua estreita vinculação com a temática abordada, cumpre referir a circunstância elementar, inobstante habitualmente desconsiderada, de que o Direito não assegura, por si só, os recursos indispensáveis para a existência humana, já que meramente pode oferecer critérios para uma distribuição dos bens materiais. Neste sentido, constata-se que a proteção do conteúdo das posições jurídicas na esfera social não poderá apenas ser desenvolvida a partir da ordem jurídica, mas deverá também levar em conta as circunstâncias sócio-econômicas vigentes, dependendo, de modo especial, da receptividade política relativamente a determinadas medidas por parte do poder público e da concepção vigente de justiça social. ${ }^{81}$

Por derradeiro, mesmo atentando para as diversidades em absoluto irrelevantes entre o sistema germânico e a

81. Esta, em suma, a liçăo de B. Schulte, in_ZIAS 1988. pp. 215 e ss. nossa ordem constitucional, esperamos que tenhamos logrado demonstrar que a análise da experiência germânica já terá valido a pena caso tiver contribuído para colocar em evidência a necessidade de, também entre nós, zelarmos por uma proteção dos níveis vigentes de segurança social. Não hesitamos, portanto, em afirmar que o princípio fundamental da proibição (relativa) de retrocesso na esfera social, seja ele implementado por meio do reconhecimento de "cláusulas pétreas", seja ela desenvolvido implicitamente a partir de outros princípios constitucionais, constitui-se não apenas em salvaguarda do Estado Social de Direito ou, caso preferirmos, da justiça material, mas principalmente da própria dignidade da pessoa humana, valor-guia de toda a ordem constitucional e objetivo permanente de toda ordem jurídica que se pretenda legítima.

\section{Referências bibliográficas:}

1 - BADURA, Peter. Eigentum, in: E. Benda/W. Maihofer/H.-J. Vogel (Org). Handbuch des Verfassungsrechts. $2^{\mathrm{a}}$ ed., Berlin: Walter de Gruyter, 1994, pp. 57 e ss.

2-BARGEN, Joachim von. Restriktive Tendenzen im Sozialhilferecht - Am Beispiel des Regelsatzes. in: W. Brandt/H, Gollwitzer/J,F. Henschel (Org). Ein Richter, ein Bürger, ein Christ - Festschrift für Helmut Simon. Baden-Baden: Nomos, 1987, pp. 745 e ss.

3 - BARROS, Suzana de Toledo. O Princípio da Proporcionalidade e o Controle de Constitucionalidade das Leis Restritivas de Direitos Fundamentais. Brasília: Ed. Brasília Jurídica, 1996.
4 - BOECKEN, Winfried. Der verfassungsrechtliche Schutz von Altersrentenansprüche und Anwartschaften in Italien und in der Bundesrepublik Deutschland sowie deren Schutz im Rahmen der Europäischen Menschenrechtskonvention. Berlin: Duncker \& Humblot, 1987.

5-BONAVIDES, Paulo. Curso de Direito Cons titucional. $7^{\text {a }}$ ed., São Paulo: Malheiros, 1997.

6-BRYDE, Brunn-Otto. Anmerkungen zu Art. 14 GG. in: Ingo von Münch/P. Kunig (Org). Grundgesetz-Kommentar. vol. I, $4^{\mathrm{a}}$ ed., München: C.H. Beck, 1992.

7 - CANOTILHO, José Joaquim Gomes. Direito Constitucional e Teoria da Constituição. Coimbra: Almedina, 1998.

8 - DEPENHEUER, Otto. Wie sicher ist verfassungsrechtlich die Rente? - Vom liberalen zum solidarischen Eigentumsbegriff. in: AÖR nº 120 (1995), pp. 417 e ss.

9 - EICHENHOFER, Eberhard. Der verfassungsrechtliche Schutz von sozialversicherungsrechtlichen Anrechten in der Bundesrepublik Deutschland, Italien und den USA. in: ZIAS 1988, pp. 231 e ss.

10 - FRIAUF, Karl Heinrich. Der Sozialstaat des Grundgesetzes unter den Bedingungen der Industriegesellschaft. in: Sozialstaat - Idee und Entwicklung, Reformzwänge und Reformziele. Köln: Wirtschaftsverlag Bachem, 1996, pp. 63 e ss.

11 - HAVERKATE, Görg. Eigentumsschutz und Weiterentwicklung im Recht der sozialen Sicherheit. in: ZRP 1984, pp. 217 e ss.

12 - HESSE, Konrad. A Força Normativa da Constituição. Porto Alegre: Ed. Sérgio A. Fabris, 1991.

13 - JARASS, Hans D. e PIEROTH, Bodo. Grunsgesetz für die Bundesrepublik Deutschland. $3^{\mathrm{a}}$ ed., München: C.H. Beck, 1995.
14 - KATZENSTEIN, Dietrich. Die bisherige Rechtssprechung des Bundesverfassungsgericht zum Eigentumsschutz sozialrechtlicher Positionen. in: W. Brandt/H. Gollwitzer/J.F. Henschel (Org). Ein Richter, ein Bürger, ein Christ - Festschrift für Helmut Simon. Baden-Baden: Nomos, 1987, pp. 847 e ss.

15 - LEISNER, Walter. Eigentum. in: J. Isensee/ P. Kirchhof (Org). Handbuch des Staatsrechts der Bundesrepublik Deutschland. vol. VI, Heidelberg: C.F. Müller, 1992, pp. 1023 e ss.

16 - PAPIER, Hans-Jürgen. Anmerkungen zu Art. 14 GG. in: Maunz/Dürig/Herzog/ Scholz, Grundgesetz Kommentar. Vol. II, München: C.H. Beck, 1994.

17 - RIETTSTIEG, Helmut. Anmerkungen zu. Art. 14-15 GG. in: R. Wassermann (Org). Kommentar zum Grundgesetz für die Bundesrepublik Deutschland (Alternativkommentar). vol. I, $2^{\text {a }}$ ed., Neuwied: Luchterhand, 1989.

18 - ROSANVALLON, Pierre. A Crise do Estado-Providência. Goiânia: Ed. UNB, 1997.

19 - SARLET, Ingo Wolfgang. A Eficácia dos Direitos Fundamentais. Porto Alegre: Ed. Livraria do Advogado, 1998.

20 - SCHLENKER, Rolf - Ulrich. Soziales Rückschrittsverbot und Grundgesetz. Berlin: Duncker \& Humblot, 1986.

21 - SCHULTE, Bernd. Bestandschutz sozialer Rechtspositionen - Eine rechtsvergleichende Betrachtung. in: ZIAS 1988, pp. 205 e ss.

22 - SCHULTE, Bernd. Wie sicher ist die soziale Sicherung? International-vergleichende Perspektive. in: B. Riedmüller/M. Rodenstein (Org). Wie sicher ist die soziale Sicherung? Frankfurt a.M.: Suhrkamp, 1989, pp. 321 e ss.

23 - STUMM, Raquel Denise. O Princípio da Proporcionalidade no Direito Constitucional 
Brasileiro. Porto Alegre: Ed. Livraria do Advogado, 1995 .

24 - WENDT, Rudolf. Anmerkungen zu Art. 14 GG. in: M. Sachs (Org), Grundgesetz Kommentar. München: C.H. Beck, 1996.
25 - ZACHER, Hans-Friedrich. Das soziale Staatsziel. in: J. Isensee/P. Kirchhof (Org.), Handbuch des Staatsrechts der Bundesrepublik Deutschland. Vol. I, Heidelberg: C.F. Müller, 1987, pp. 1045 e ss.

\section{Do Positivismo Jurídico à Democracia em Kelsen}

\author{
Losé Levi e Mello do eAmaxal Líniose
}

Professor de Direito Constitucional da PUC/RS

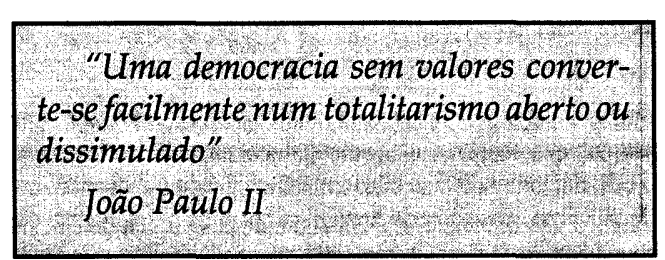

\begin{tabular}{|c|}
\hline SUMÁRIO \\
1. Introdução; \\
2. O conceito de Direito em Kelsen; \\
3. O jogo democrático em Kelsen; \\
4. Cruzando o limiar da democracia \\
kelseniana; \\
5. Referências bibliográficas. \\
\hline
\end{tabular}

\section{Introdução}

ANS KELSEN, provavelmente o maior jurista do Século XX, tem recebido toda sorte de interpretações e críticas. Afinal, sua vasta e singularmente articulada obra é alvo dos mais sérios debates doutrinários das últimas décadas. Analisar o conceito de Direito em KELSEN, bem como seus reflexos na concepção de democracia proposta pelo mesmo autor, é o objeto do presente estudo.

Para isso, iniciaremos enfrentando o conceito de Direito em KELSEN; a seguir estudaremos o modelo democrático por ele defendido; à guisa de conclusão, enfocaremos a forma pela qual a concepção de Direito exposta determina a teoria kelseniana de Estado democrático, a fim de precisar a influência daquele conceito sobre a dinâmica do jogo democrático tal qual proposto pelo jurista austríaco.

\section{0 conceito de Direito em Kelsen}

O dissenso e o embate ideológico marcam, profundamente, a sociedade 